\title{
GREEN SYNTHESIS OF NANOSILVER FOR GELATIN FILMS WITH ANTIMICROBIAL PROPERTY PREPARATION
}

Rodrigues, M. L. L. ', *; Pires, N. R. ${ }^{\text {; }}$ Vasconcelos, N. F. ; Feitosa, J. P. A. '; Oliveira, E. S. ${ }^{2}$; Filho, M. S. M. S. ${ }^{3}$; Morais, J. P. S. ${ }^{3}$

${ }^{1}$ Department of Chemistry Organic and Inorganic, UFC, Fortaleza, CE, Brazil

2 Department of physics, UFC, Fortaleza, CE, Brazil

${ }^{3}$ EMBRAPA Tropical Agroindustry, Fortaleza, CE, Brazil

*marialinharesr@hotmail.com

\begin{abstract}
Nanomaterials can play an important role in antibacterial applications. Various nanostructured metallic particles have been used for nanocomposite packaging materials. Silver nanoparticles (AgNPs) are regarded as an antibacterial agent for food package. The objective of this study was to prepare antimicrobial nanocomposite films using gelatin and AgNPS. Gelatin was used as a polymer matrix for reduction and stabilization of the silver nanoparticles. Films were characterized by XRD, XRF, UV-Vis, FTIR, and antibacterial activity. Gelatin $(3.0 \mathrm{~g})$ was stirred at $\sim 90^{\circ} \mathrm{C}$ for $30 \mathrm{~min}$. The $\mathrm{pH}$ of the solutions was adjusted to $\mathrm{pH} 11$, then $1 \mathrm{~mL}$ of $\mathrm{AgNO}_{3}$ at various concentrations $(0,45,90$, and $180 \mathrm{mmol} . \mathrm{L}^{-1}$ ) was added drop-wise into the solution mixtures. The neat gelatin (gel) and gel/AgNPs $45 \mathrm{mmol} . \mathrm{L}-1$ films did not show any UV-Vis absorption peak in $\sim 430 \mathrm{~nm}$, but gel/AgNP $90 \mathrm{mmol} . \mathrm{L}^{-1}$ and gel $/ 180 \mathrm{mmol} . \mathrm{L}^{-1}$ films exhibited a high absorption peak, which is related to the collective oscillations of the surface electrons. All FTIR peaks of the gel control and of the gel/AgNP show similar spectrum. The higher AgNPs concentration in the films, the higher the antibacterial activity against food-borne pathogens. The X-ray diffractograms of films was carried out for identifying crystalline phases by PANalytical X'pert High-Score Plus software, in which, showed the presence the peaks position (2) at $32.2^{\circ}, 54.7^{\circ}, 55.5^{\circ}$ and $74.6^{\circ}$ to gel/AgNPs $90 \mathrm{mmol} \cdot \mathrm{L}^{-1}$ and $11.7^{\circ}, 28.5^{\circ}, 50.5^{\circ}$ to 180 mmol. $\mathrm{L}^{-1}$ for silver. But wasn't possible identify to gel/AgNPs $45 \mathrm{mmol} . \mathrm{L}^{-1}$, because the low concentration. Was possible to produce crystalline silver nanoparticles in the gelatin films and obtain films with antimicrobial activity.
\end{abstract}

